\title{
EXTRACTION OF CELLULOSE FROM SAWDUST BY USING IONIC LIQUID
}

\author{
Wan SulwaniIzzatibinti Wan BaderulHisan, *IndokNurulHasyimahMohd Amin \\ Chemical Engineering Technology in Process, \\ University Kuala Lumpur Malaysian Institute of Chemical And Bioengineering Technology, \\ Alor Gajah, Melaka \\ sulwani.baderul@s.unikl.edu.my \\ *nurulhasyimah@unikl.edu.my
}

\begin{abstract}
Cellulose is one of the major constituent of all plant materials, which formed about half to one-third of all plant tissues and constantly fill up again by photosynthesis process. One of the objectives for this project is to extract cellulose from sawdust by using ionic liquid. The ionic liquid used was called Dimethyl Sulfoxide (DMSO) which be functioning as to break the lignin wall from the organic samples. In the extraction process, the 5 samples of sawdust had been immersed into the DMSO and stirred for about 1.5 hours on the hot plate at $50^{\circ} \mathrm{C}$. Then, the dissolution of the sawdust has been observed where the colour of the mixture became darker and the viscosity was increased due to the dissolution of the wood.. Next, to characterize the sample, Fourier Transform Infrared (FTIR) spectroscopy has been analyzed for cellulose rich extract and brownish liquor called lignin. The difference of IR spectra for cellulose rich extract has been detected where the difference between the peaks. Then the moisture content of the cellulose rich extract obtained shows that the lower the mass of the sawdust, the higher the moisture content obtained. Lastly the particle size analysis also has been analyzed where the volume of mesopores in the sample was higher than the micropore and macropore. . As the conclusion, the extraction of cellulose from sawdust by using DMSO has been done well and the cellulose was successfully been extracted while the lignin has been separated from the wood. In addition, the cellulose rich extract obtained can be used for further research as for example production of cellulose membrane nanofibers.
\end{abstract}

Keyword-sawdust, DMSO, FTIR, IR spectra, ionic liquid, cellulose, lignin

\section{INTRODUCTION}

.Cellulose is one of the major constituent of all plant materials, which formed about half to one-third of all plant tissues and constantly fill up again by photosynthesis process. According to [5], the most abundant lignocellulosic resource on Earth is wood. The main component of wood is a macromolecular substance with $40-50 \%$ cellulose, $15-25 \%$ hemicellulose and $15-30 \%$ [7]. Cellulose has been used as a raw material for the production of paperboard, paper, fibreboard and any similar product.

The excellent characteristics of the cellulose which include the biodegradability and the capacity for the broad chemical modification will increased the interest and encourage the worldwide research on cellulose over the past few decades. [7-1]. Mostly in the natural plant, the crystalline cellulose is fixed with cellulose, hemicellulose and lignin which make the process difficult to obtain pure cellulose [6].

In these recent years, the interest of the research in the cellulose based-materials has been increasing due to the demand for the renewable resources and growing on environmental awareness. [3]. Natural cellulose fibers become greater in being used as one of the materials in thermoset and thermoplastics polymeric matrices instead of glass fibers because of their characteristics which are renewability, low density and high specific strength. There are several plants such as wood, cotton, bamboo and hem that rich with cellulose content. There are several plants such as cotton, wood, bamboo, flax, hemp, sisal, and jute that are rich in cellulose. In addition, in the last decade the use of cellulosic waste as a filler has been focused in several research has been growing up rapidly.

Many of the agriculture wastes materials such as coconut husk fibers, banana leaves, banana stem, and soy bean have been studied as a raw material in the production of cellulose fiber. Although a variety of natural fibers were investigated in detail, the use of sawdust as a natural source for the production of cellulose has not been explored yet. 


\section{MATERials AND Methods}

\section{A. Materials}

The raw material whish was the sawdust were obtained from furnishing shop at Kajang, Selangor. The sawdust were carefully selected to avoid choosing any toxin in the wood material that will influence the extraction of cellulose process. The sawdust was fresh and look light brownish colour where the owner of the shop mentioned, the sawdust is from Scaphium spp. (KayuKembangSemangkok). The sawdust has been grinded into powder which will make the process more easier.

Dimethyl sulfoxide was used to break the lignin wall from the wood and to produce electrospun cellulose fibers. DMSO is a colourless liquid which is a polar aprotic solvent where can dissolves both polar and nonpolar compounds. Besides that, DMSO also has been used widely range miscible in organic solvent as well as water. The unusual property in the DMSO perceive a garlic-like taste in mouth after contact with the skin.

\section{B. Methods}

1) Preparation of Sawdust: Scaphium spp. wood samples were obtained from Furnishing Shop Kajang, Selangor. The sample first been dried directly to sunlight and cut into a small pieces. Next, the small pieces of wood chips were ground into powder using grinder. Then, the sawdust was dried overnight in vacuum oven at $100^{\circ} \mathrm{C}$ before using. In the Figure 3.2 show that the small pieces of wood chip has been ground and prepared for drying process.

2) Dissolution of Wood: Dimethyl Sulfoxide (DMSO) in liquid form was prepared for stirred with the sawdust. In dissolution process, 5 different mass of sawdust has been prepared which were in $2 \mathrm{~g}, 4 \mathrm{~g}, 8 \mathrm{~g}$ and $10 \mathrm{~g}$. then, all the samples were dispersed into $190 \mathrm{~g}$ of DMSO in a $100 \mathrm{ml}$ beaker. The mixture was magnetic stirred on a hot plate at $50^{\circ} \mathrm{C}$ in the open atmosphere. All the mixture has been stirred with speed of 3 and duration in 1.5 hours. A dark and viscous wood suspension with about 5 wt\% wood concentration were obtained.

3) The Extraction of Cellulose and Lignin: After the dissolution process, all the samples were filtered through filter paper to remove undissolved residue which was the cellulose rich extract. Then some of the extract and the undissolved residue were dried overnight in vacuum oven at $100^{\circ} \mathrm{C}$ for later use. While the clear brownish liquid that been filtered was called lignin.

\section{III.RESULTS AND DISCUSSION}

\section{A. Dissolution of Sawdust in DMSO}

After the mixture was been heated a few hours at $50^{\circ} \mathrm{C}$ under magnetic stirrer with speed of 3 , the colour of the mixture became darker and the viscosity was increased distinctively which indicating the dissolution of the sawdust has been occurred. After the filtration process, a clear, dark brownish solution was obtained. For the brown gel residue obtained from the filtration indicate the cellulose rich extract.

The observation has been made while the dissolution process of sawdust occurred. The result shows that the sawdust samples were at their original states and the fibrous structures can be observed below $30^{\circ} \mathrm{C}$. The swelling process occurred at $40^{\circ} \mathrm{C}$ and the dissolution been observed at $50^{\circ} \mathrm{C}$.

The rate of dissolution increased at $50^{\circ} \mathrm{C}$ where at this temperature, the most of fibrous material has been disappeared after 5 minutes and the visual field became darker. After 30 minutes at $50^{\circ}$, there were no change with the solution and a fully black field was not obtained even the reaction time has been increased to two hours. In this case, the experiments indicate that DMSO can only partially dissolve the sawdust.

\section{B. Fourier Transform Infrared (FTIR) Spectroscopy Analysis}

1) Cellulose Rich Extract: For the FTIR analysis, the IR spectra of the cellulose rich extract were obtained from the sawdust residue from different weight had been compared. Figure 1 shows the IR spectra of the cellulose rich extract that obtained. The broad range of peaks that was around $3300-3400 \mathrm{~cm}-1$ in the spectra were indicate the stretching vibrations of the $\mathrm{O}-\mathrm{H}$ bonds of water molecules which were absorbed onto the matrices of the samples. The appearance of the peaks between the regions from 1500 to 1600 $\mathrm{cm}-1$ shows that the presence of $\mathrm{C}=\mathrm{C}$ bonds of aromatic compounds. Meanwhile, for the broad peaks which has been observed around the region of 1050-1070 cm-1 which could be indicate to the stretching vibrations of the C-O bonds of alcohols, phenols, esters and ethers. 


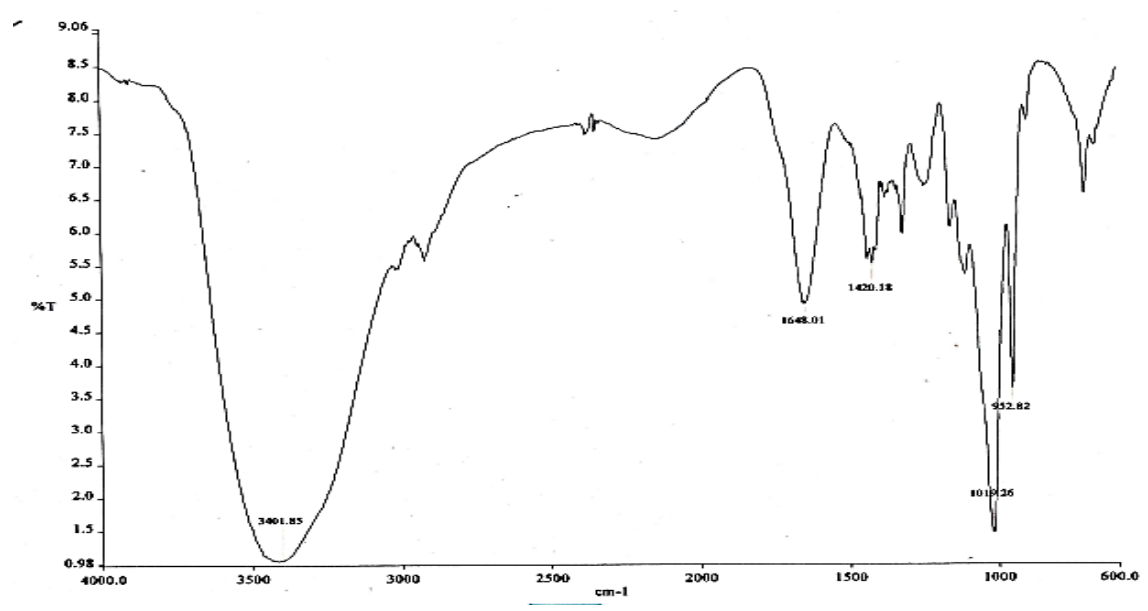

Fig. 1. The IR spectra for cellulose rich extract.

2) Lignin: A clear brownish colour solution that obtained from the filtration process is called lignin. The residual lignin content in the solution were determined by using FTIR. The IR spectra of the lignin was obtained and been compared. The characteristics peaks of lignin were observed around $1500 \mathrm{~cm}-1$ which indicate $\mathrm{C}=\mathrm{C}$ stretching vibrations aromatic bonds of the compound. While the broad peaks between $1458 \mathrm{~cm}-1$ and $1261 \mathrm{~cm}-1$ shows the asymmetric bending in CH3 and indicate guaiacyl ring of the component [1]. After comparing the IR spectra between the original sawdust and the sawdust residue, the graph shows the cellulose and the lignin peaks. However after the filtration process, the lignin peaks is less noticeable in the cellulose rich extract compared to the original sawdust. Meanwhile during IR spectra for the lignin, the peaks for lignin is more abroad which shows that the breakdown of lignin from the sawdust is successful. This result also conclude that the most of the lignin is reserved in the saw dust which the main component of the extract is cellulose.

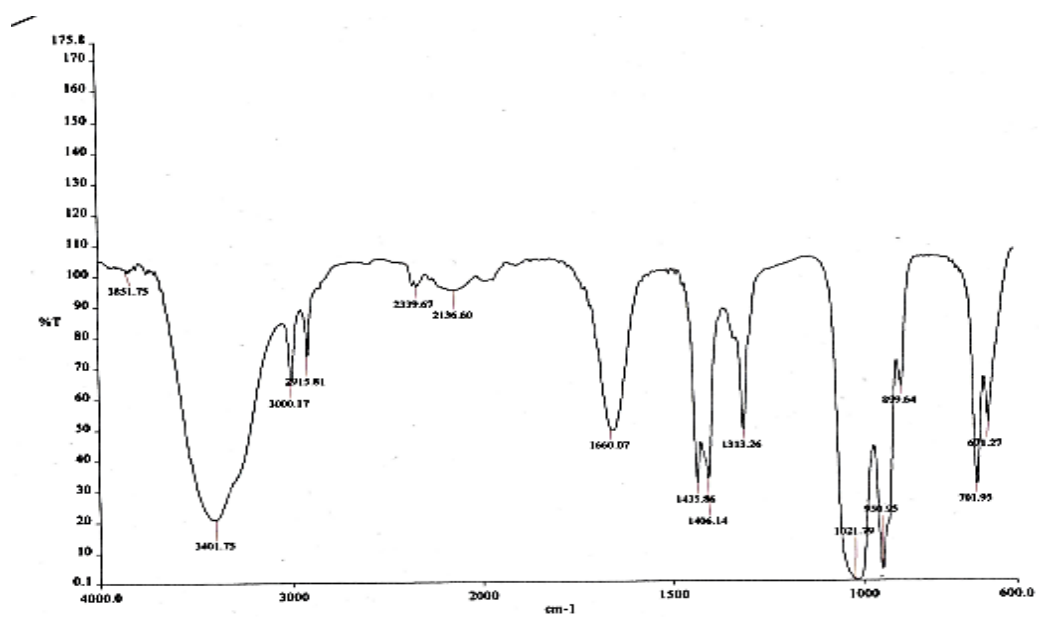

Fig.2. The IR spectra for brownish liquor lignin.

3) Moisture Content: After the characterization of cellulose rich extract in the FTIR, the samples were weighed on the mass balance before being dried in vacuum oven overnight at $100^{\circ} \mathrm{C}$. After being dried overnight, the samples were weighed on mass balance to calculate the moisture lost. Figure 3 shows that the graph of moisture content of wet basis against mass of sawdust. 


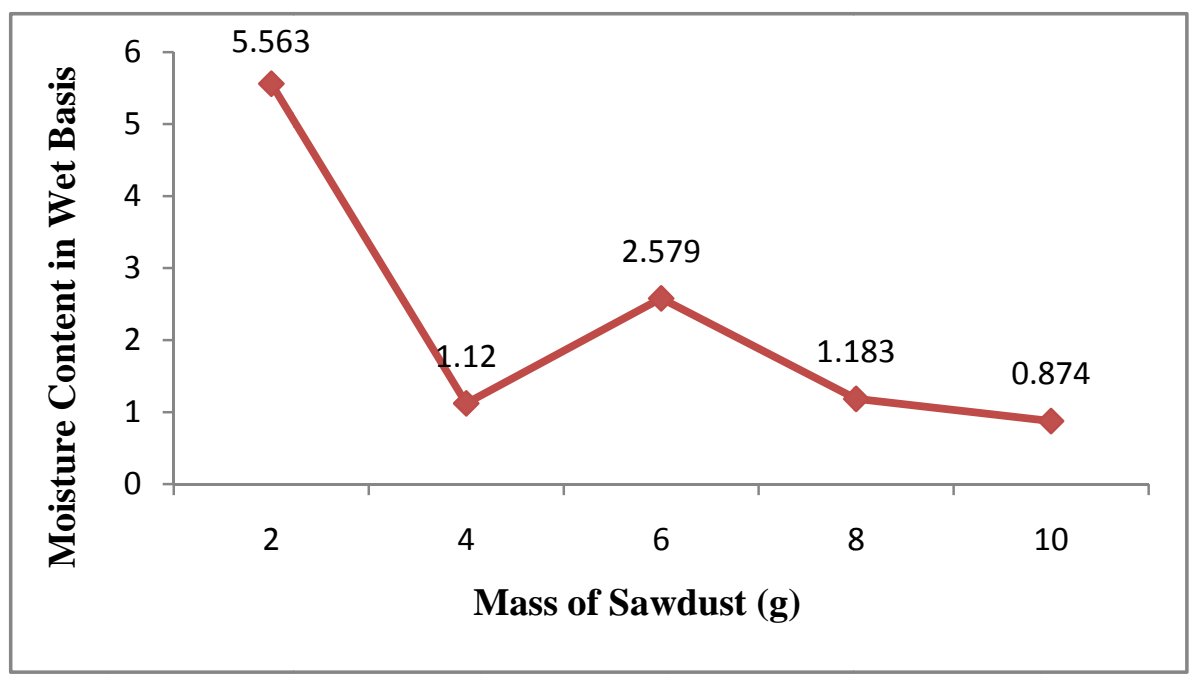

Fig.3. Graph of Moisture Content of Wet Basis against Mass of Sawdust.

4) Particle Size Analysis: For the particle size analysis, the result obtained shows that the volume percentage of particle size were more towards to the size in the range of 10 to $100 \mu \mathrm{m}$ which contain macropore and mesopore. The volume in percentage was higher which was $7.75 \%$ at the point size of $24.808 \mu \mathrm{m}$. Figure 3 below shows that the result of the particle size analysis for the cellulose rich extract.

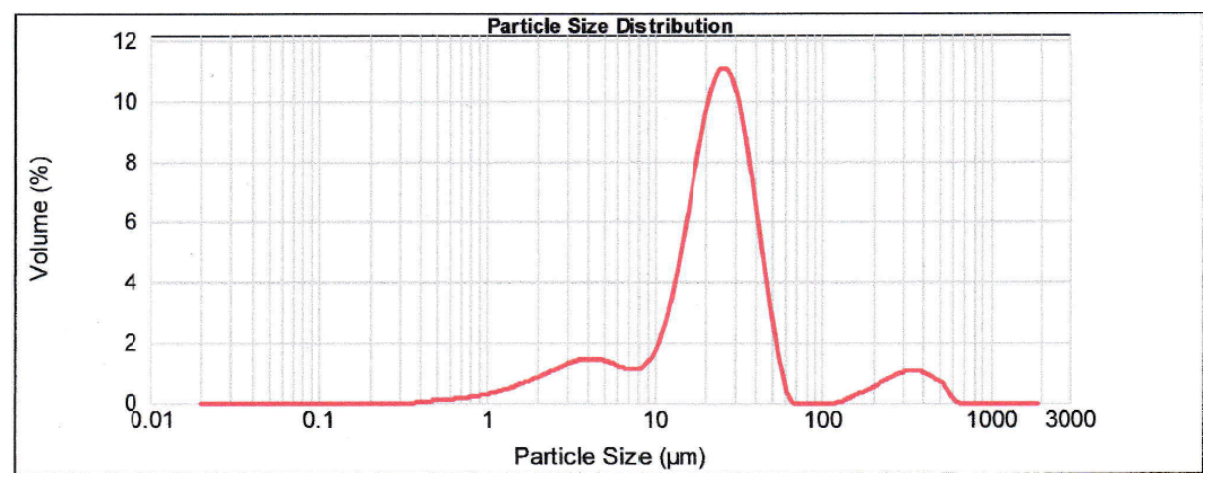

Fig.4. Particle Size Analysis for Cellulose Rich Extract

\section{IV.CONCLUSION}

The extraction of cellulose from sawdust by using ionic liquid which was Dimethyl Sulfoxide (DMSO) was done successfully. The lignin has been break from the sawdust and the residue became cellulose rich extract. The IR spectra of the cellulose rich extract obtained shows confirmed the removal of lignin by loss of peak at $1514 \mathrm{~cm}-1$ which indicated the $\mathrm{C}=\mathrm{C}$ stretching vibrations double bonds of lignin. The color of the mixture during dissolution of sawdust changed to dark brown shows the sawdust were swollen and the dissolution process occur. In conclusion, cellulose rich extract that obtained from the sawdust can be used as one of the elements in further research such as use the cellulose as production of cellulose nanofiber membrane where the cellulose has been extracted from the organic material.

\section{REFERENCES}

[1] Heinze, T., Liebert, T., 2001. Unconventional methods in cellulose functionalization. Prog. Polym. Sci. 26, 1689-1762.

[2] Johar, N., Ahmad, I., \& Dufresne, A. (2012). Extraction, preparation and characterization of cellulose fibres and nanocrystals from rice husk. Industrial Crops and Products, 37(1), 93-99. http://doi.org/10.1016/j.indcrop.2011.12.016

[3] Mohanty, A.K., Misra, M, Drzal, L.T, Selke, S.E., Harte, B.R., Hinrichsen, G., 2005. Natural fibers, Biopolymers and Biocomposites: An Introduction, in "Natural Fibers, Biopolymers and Biocomposites”. In: Mohanty, A.K., Misra, M., Drzal, L.T. (Eds.). CRC Press, London.

[4] Oliveira, J. P. de, Bruni, G. P., Lima, K. O., Halal, S. L. M. El, Rosa, G. S. da, Dias, A. R. G., \&Zavareze, E. da R. (2017). Cellulose fibers extracted from rice and oat husks and their application in hydrogel. Food Chemistry, 221, 153-160. http://doi.org/10.1016/j.foodchem.2016.10.048

[5] Penjumras, P., Rahman, R. B. A., Talib, R. A., \&Abdan, K. (2014). Extraction and Characterization of Cellulose from Durian Rind. Agriculture and Agricultural Science Procedia, 2, 237-243. http://doi.org/10.1016/j.aaspro.2014.11.034

[6] Rachtanapun, P., Luankamin, S., Tanprasert, K., Suriyaterm, R., 2012. Carboxymethyl Cellulose Film from Durian Rind. LWT-Food Science and Technology 48(1), 52-58. 
[7] Sun, N., Rahman, M., Qin, Y., Maxim, M.L., Rodriguez, H., Rogers, R.D., 2009. Complete dissolution and partial delignification of wood in the ionic liquid 1- ethyl-3-methylimidazolium acetate. Green Chem. 11, 646-655.

[8] Voitl, T., Nagel, M.V., Rohr, P.R., 2010. Analysis of products from the oxidation of technical lignins by oxygen and H3PMo12O40 in water and aqueous methanol by size-exclusion chromatography. Holzforschung 64, 13-19

[9] Wang, X., Li, H., Cao, Y., \& Tang, Q. (2011). Cellulose extraction from wood chip in an ionic liquid 1-allyl-3-methylimidazolium chloride (AmimCl). Bioresource Technology, 102(17), 7959-7965. http://doi.org/10.1016/j.biortech.2011.05.064

[10] Tolba, G. M. K., Bastaweesy, A. M., Ashour, E. A., Abdelmoez, W., Khalil, K. A., \&Barakat, N. A. M. (2015). Effective and highly recyclable ceramic membrane based on amorphous nanosilica for dye removal from the aqueous solutions. Arabian Journal of Chemistry. http://doi.org/10.1016/j.arabjc.2015.05.009

[11] Varanasi, S., Low, Z.-X., \&Batchelor, W. (2015). Cellulose nanofibre composite membranes - Biodegradable and recyclable UF membranes. Chemical Engineering Journal, 265, 138-146. http://doi.org/10.1016/j.cej.2014.11.085

[12] Wandera, D., Himstedt, H. H., Marroquin, M., Wickramasinghe, S. R., \&Husson, S. M. (2012). Modification of ultrafiltration membranes with block copolymer nanolayers for produced water treatment: The roles of polymer chain density and polymerization time on performance. Journal of Membrane Science, 403-404, 250-260. http://doi.org/10.1016/j.memsci.2012.02.061

[13] Weschenfelder, S. E., Louvisse, A. M. T., Borges, C. P., Meabe, E., Izquierdo, J., \& Campos, J. C. (2015). Evaluation of ceramic membranes for oilfield produced water treatment aiming reinjection in offshore units. Journal of Petroleum Science and Engineering, 131, 51-57. http://doi.org/10.1016/j.petrol.2015.04.019

[14] Yalçin, N., \&Sevinç, V. (2001). Studies on silica obtained from rice husk. Ceramics International, 27(2), $219-224$. http://doi.org/http://dx.doi.org/10.1016/S0272-8842(00)00068-7

[15] Zabolotsky, V., Utin, S., Bespalov, A., \& Strelkov, V. (2015). Modification of asymmetric bipolar membranes by functionalized hyperbranched polymers and their investigation during $\mathrm{pH}$ correction of diluted electrolytes solutions by electrodialysis. Journal of Membrane Science, 494, 188-195. http://doi.org/10.1016/j.memsci.2015.07.057 